\title{
Diseminasi dan Publikasi Karya Tulis Berbasis Media Baru
}

\author{
Eka Nada Shofa Alkhajar ${ }^{1)}$, Agusniar Rizka Luthfia ${ }^{2)}$ \\ Program Studi Ilmu Komunikasi, Fakultas Ilmu Sosial dan Ilmu Politik, \\ Universitas Sebelas Maret, Indonesia ${ }^{1)}$ \\ Program Studi Ilmu Administrasi Negara, Fakultas Ilmu Sosial dan Ilmu Politik, \\ Universitas Sebelas Maret, Indonesia ${ }^{2)}$ \\ Pos-el : ekanadashofa@staff.uns.ac.id
}

Dikirim: 24, 07, 2020

Direvisi: $11,08,2020$

Diterbitkan: 31, 08, 2020

\begin{abstract}
Abstrak
Pengabdian kepada masyarakat berbentuk workshop ini bertujuan untuk memberikan informasi mengenai cara mendiseminasikan dan mempublikasikan karya tulis fiksi dari mitra kegiatan. Kegiatan pengabdian ini dilaksanakan berdasarkan analisis situasi yang dilakukan tim pengabdian di mana mitra kegiatan memerlukan workshop berkaitan dengan hal tersebut. Kegiatan pengabdian ini diselenggarakan dalam dua sesi. Sesi pertama dikonsentrasi untuk pemaparan materi mengenai diseminasi dan publikasi. Sementara, sesi kedua difokuskan kepada pembuatan weblog. Kedua sesi tersebut diselenggarakan dengan metode ceramah, diskusi dan pendampingan. Mitra kegiatan mengikuti workshop dengan ketertarikan yang besar. Adapun hasil yang dicapai dari kegiatan pengabdian kepada masyarakat ini adalah mitra kegiatan memiliki pengetahuan dan keterampilan untuk mendiseminasikan dan mempublikasikan karya tulis fiksinya dengan cara yang tepat.
\end{abstract}

Kata Kunci: workshop, diseminasi, publikasi, weblog

\section{Abstract}

The workshop-shaped community devotion aims at providing information on how to disseminate and publish fiction writings produced by the target of community devotion. This is achieved on the basis of the devotion team situational analysis that the target need such workshop. The community devotion is held in two sessions. The first session concentrated on material presentation related to disemination and publication. The second session focused on weblog creation. These two sessions were carried out with lectures, discussions, and accompaniments methods. The target of community devotion joined the workshop with great interest. The result achieved from this community devotion is that the target of community had the knowledge and skills to disseminate and publish their fiction writings properly.

Keywords: workshop, dissemination, publication, weblog

\section{PENDAHULUAN}

Menurut para pakar, masa remaja adalah salah satu dari fase kehidupan manusia yang penuh dengan gejolak. Ini adalah fase kritis di mana para remaja tengah mencari jati dirinya. Fase ini juga dikenal sebagai masa transisi dari kehidupan anak-anak menuju dewasa (Santrock, 2010; Shaffer dan Kipp, 2010; Sarwono, 2011; Santrock, 2013). Selain itu, fase remaja juga ditengarai sebagai fase yang penuh tantangan di mana tak jarang remaja justru 
terjebak kepada hal-hal yang negatif seperti narkoba, tawuran, miras, pergaulan bebas hingga kenakalan remaja lainnya (Alkhajar, 2007; Alkhajar 2014; Luthfia et al., 2019b). Persoalan budi pekerti dan akhlak di kalangan remaja pun kian menjadi catatan tersendiri di mana halhal tersebut dirasa sudah mulai terdegradasi. Bahkan kini tidak sedikit remaja yang telah kehilangan tata krama dan sopan santunnya.

Apalagi kini arus informasi berlangsung dengan sangat deras. Informasi positif maupun negatif bertebaran di mana-mana. Remaja yang memiliki kemampuan literasi media yang baik akan mampu menyaring mana informasi yang baik dan mana informasi yang buruk. Akan tetapi, pada kenyataannya kemampuan semacam itu masih jarang dimiliki kalangan remaja. Belum lagi, media televisi kita melalui sinetron remajanya masih kerap menampilkan representasi remaja yang tidak mendidik di mana porsi cerita cinta remaja yang tak pantas justru masih menjadi sajian utamanya. Kondisi semacam ini bahkan telah terjadi sejak lama, terus berulang dan terus terjadi hingga kini (Wirodono, 2005; Alkhajar, 2009; Alkhajar, 2010).

Kita tentunya sangat menyayangkan tampilan remaja semacam itu justru kerap hadir di layar kaca. Padahal tayangan remaja berkualitas rendah tersebut jelas jauh sekali dari kesan mendidik. Belum lagi banyak remaja kita yang mengonsumsi tayangan remaja yang berkualitas rendah tersebut. Persoalannya adalah tayangan tersebut ikut berkontribusi dalam memberikan sebuah penggambaran remaja yang tidak akurat sehingga menyebabkan remaja terjebak dalam realitas semu dan menganggap gambaran remaja semacam itulah dunia remaja yang sesungguhnya (Alkhajar, 2007). Hal ini tentu dapat menjadi sesuatu yang sangat berbahaya bagi remaja.

Kita semua tentu berharap agar televisi kita dapat lebih banyak menampilkan representasi remaja yang ideal yakni sarat akan akhlak, nilai-nilai baik dan budi pekerti yang luhur. Dengan kata lain, televisi dapat lebih berperan dalam penanaman pendidikan karakter bagi generasi muda. Peran ini bukanlah sesuatu yang mustahil karena televisi sebagai sebuah media memang memiliki kemampuan yang hebat untuk ikut mencerdaskan kehidupan bangsa ataupun sebaliknya menghancurkan sebuah bangsa (Alkhajar, 2011).

Melihat peliknya persoalan dan tantangan yang harus dihadapi remaja, kita sebagai bagian dari masyarakat tentu tidak boleh hanya berpangku tangan dan berdiam diri. Upaya sekecil apapun harus dapat kita lakukan untuk membimbing dan mendampingi remaja melalui fase remajanya secara positif. Salah satu upaya yang dapat kita lakukan adalah dengan melaksanakan kegiatan pengabdian kepada masyarakat di mana mitra kegiatannya adalah para remaja. Sebagaimana diketahui, remaja yang memperoleh pendampingan yang baik terbukti dapat berkontribusi dan terlibat dalam berbagai bentuk kegiatan positif serta turut menebarkan pesan-pesan kebaikan. Mulai dunia tulis-menulis hingga aktif berperan dalam upaya penyadaran masyarakat terhadap perubahan iklim, termasuk di dalamnya melaksanakan strategi menghadapi perubahan iklim (Luthfia \& Alkhajar, 2018; Luthfia et al., 2019a; Alkhajar \& Luthfia, 2020).

Kegiatan pengabdian ini merupakan kegiatan yang berusaha menjembatani kebutuhan mitra kegiatan yakni para remaja yang merupakan para santri di Pondok Pesantren Rumah Senyum Yatim Indonesia (SETIA) untuk mendiseminasikan dan mempublikasikan karya tulis fiksi yang telah mereka hasilkan. Rumah SETIA sendiri merupakan salah satu pondok 
pesantren yang memberikan perhatian khusus kepada anak yatim. Oleh karena itu, sebagai bagian masyarakat kita pun memiliki kewajiban untuk dapat memberikan berbagai macam dukungan di mana salah satunya dapat berupa pendidikan, keterampilan ataupun pengetahuan (Muhsin, 2003; Dasuki, 2011; Luthfia et al., 2019b; Chomaria, 2014).

Berpijak pada latar belakang tersebut, kegiatan pengabdian ini diharapkan dapat memberikan pengetahuan kepada mitra kegiatan berkenaan dengan diseminasi dan publikasi karya tulis melalui media yang dirasa paling tepat untuk dipilih. Dari sini mitra kegiatan diharapkan dapat menyebarkan gagasan dan narasi yang baik kepada generasi muda lainnya melalui karya tulis fiksi ataupun karya tulis lain yang mereka hasilkan.

\section{METODE}

Pelaksanaan kegiatan pengabdian kepada masyarakat ini menggunakan metode ceramah, diskusi dan pendampingan. Metode ceramah dan diskusi digunakan dalam pemaparan materi terkait kegiatan pengabdian. Sementara itu, metode pendampingan digunakan pada saat mitra melakukan diseminasi dan publikasi karya tulis fiksi di media yang telah dipilih. Sebelumnya, tim pengabdian dan mitra kegiatan melakukan koordinasi secara intensif untuk memastikan agar kegiatan dapat berjalan dengan baik, lancar dan sesuai dengan tujuan yang telah ditetapkan sebelumnya. Kegiatan pengabdian diselenggarakan pada 23 Agustus 2019 di Pondok Pesantren Rumah SETIA Unit Putri yang berlokasi di Sukoharjo. Kegiatan pengabdian ini merupakan lanjutan dari kegiatan yang telah dilaksanakan di lokasi yang sama pada 18 Agustus 2019 berkenaan dengan pelatihan penulisan karya tulis fiksi. Adapun jumlah keseluruhan peserta yang mengikuti kegiatan pengabdian sebanyak 40 peserta.

\section{HASIL DAN PEMBAHASAN}

Sebagaimana telah disebutkan di atas, kegiatan pengabdian ini merupakan tindak lanjut (follow up) dari kegiatan yang telah dilaksanakan di lokasi dan mitra yang sama. Hal ini dimaksudkan agar ada sebuah kesinambungan antara kegiatan pengabdian sebelumnya yang berkaitan dengan penulisan karya tulis fiksi sebagai wahana artikulasi gagasan para santri yang notabenenya juga merupakan remaja atau generasi muda (Luthfia et al., 2019b). Pada kegiatan pengabdian tersebut, para santri telah mendapatkan pengetahuan mengenai dasardasar kepenulisan sekaligus proses kreatif yang diperlukan dalam menuliskan dan menuangkan gagasan ataupun ide yang mereka miliki. Di mana salah satu sumber utama gagasan atau ide tersebut diharapkan berasal pengalaman keseharian mereka (Luthfia dan Alkhajar, 2011). Dalam proses selanjutnya, mereka juga telah membuat karya tulis berbentuk fiksi yang setelah melalui tahapan diskusi, konsultasi dan memperoleh umpan balik berupa berbagai masukan, karya tulis fiksi tersebut kemudian siap untuk didiseminasikan dan dipublikasikan. Meskipun demikian, pengetahuan mengenai mitra kegiatan mengenai cara mendiseminasikan dan mempublikasikan karya tulis dapat dikatakan rendah. Dari hasil pretest yang dilakukan hanya terdapat sebanyak $40 \%$ atau 16 peserta yang memiliki pengetahuan mengenai hal tersebut. Untuk itulah, kegiatan pengabdian lanjutan ini dilaksanakan untuk meningkatkan pengetahuan sekaligus melatih mitra agar memiliki keterampilan berkaitan dengan diseminasi dan publikasi karya tulis. Hal ini juga sebagai sarana untuk meneruskan 
apa yang telah dicapai dalam kegiatan pengabdian sebelumnya sekaligus memenuhi harapan dari mitra kegiatan agar ada semacam luaran dari kegiatan yang telah dilaksanakan.

Kegiatan pengabdian berkenaan dengan diseminasi dan publikasi karya tulis ini menggunakan pendekatan interaktif penuh di mana dalam proses kegiatan pengabdian peserta dapat bertanya, berdiskusi dan berkonsultasi secara langsung dengan tim pengabdian. Pendekatan ini dirasa efektif untuk memperoleh respons maksimal dari para peserta sehingga mereka semua dapat terdorong untuk berpartisipasi aktif selama kegiatan pengabdian berlangsung. Pada sesi pemaparan materi, para peserta memperoleh informasi mengenai berbagai pilihan diseminasi dan publikasi karya tulis yang telah mereka hasilkan. Mulai dari buku, surat kabar, majalah, media baru atau media daring hingga media sosial. Dalam sesi ini juga didiskusikan mengenai bagaimana proses publikasi termasuk kelebihan dan kekurangan dari masing-masing sarana diseminasi dan publikasi tersebut.

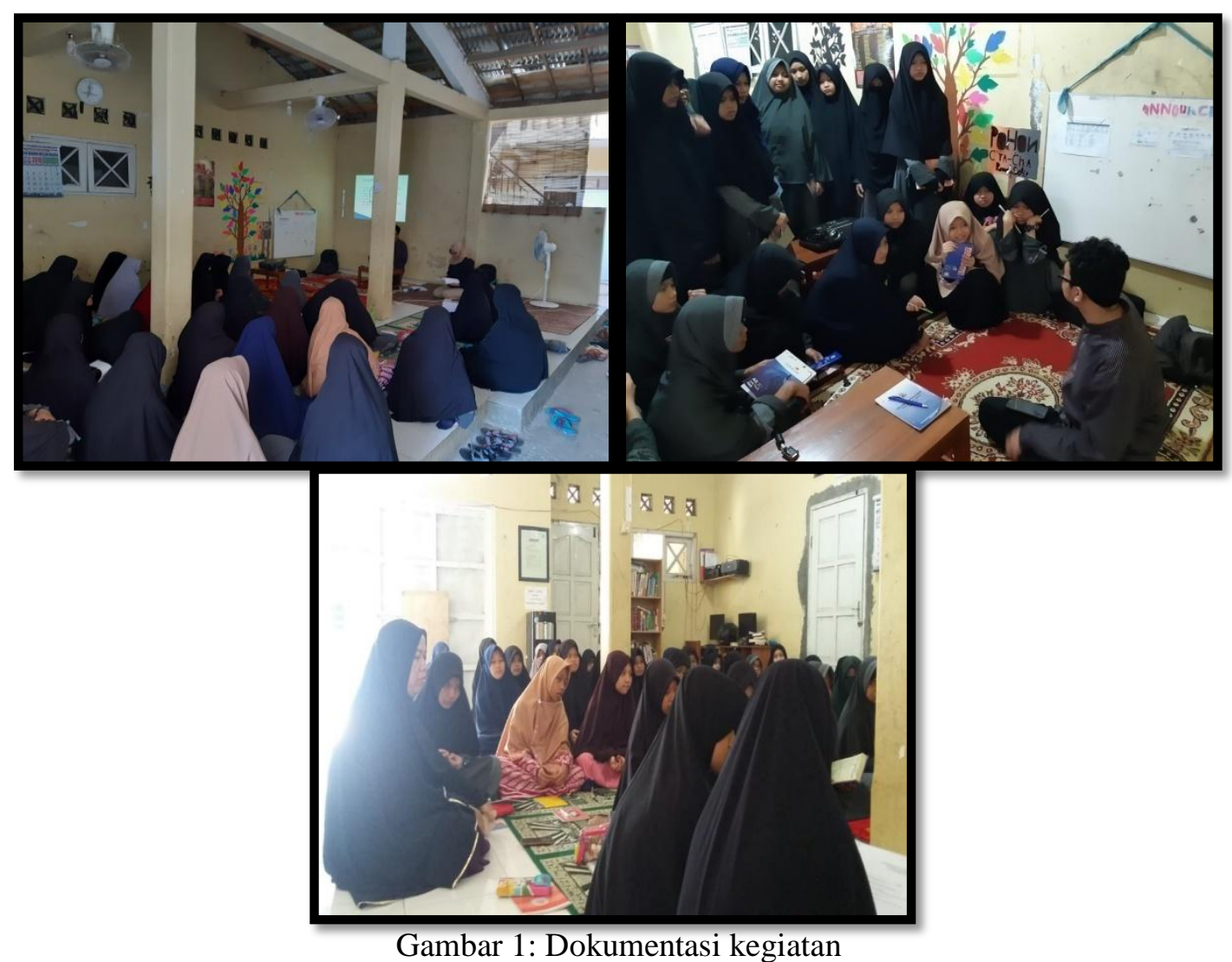

Setelah melalui tahapan sesi pemaparan materi, kegiatan pengabdian pun dilanjutkan kembali dengan proses diskusi mendalam mengenai media apa yang akan dipilih untuk mendiseminasikan dan mempublikasikan karya tulis para santri. Setelah melalui proses diskusi termasuk mempertimbangkan berbagai aspek yang ada maka tim pengabdian dan mitra pengabdian memilih media baru atau media daring berupa weblog atau blog yang tidak berbayar.

Blog berbasis WordPress.com merupakan platform yang dipilih sebagai sarana diseminasi dan publikasi karya tulis para santri sekaligus sebagai sarana atau wadah untuk untuk menyalurkan minat mereka dalam dunia tulis-menulis. Blog para santri ini berjudul 
Karya Santri dan beralamat di https://karyasantrirumahsetia.wordpress.com. Blog tersebut dapat ditemukan secara daring. Sebagaimana diketahui, blog sendiri telah lama menjadi salah satu pilihan media untuk berbagi informasi, pengetahuan, pengalaman bahkan menyuarakan gagasan, pendapat, hingga wacana oleh berbagai kalangan baik personal, kelompok, lembaga ataupun institusi. Lebih dari itu, blog bahkan telah digunakan dalam proses pembelajaran dan pendidikan di berbagai level pendidikan.

Setelah kegiatan pengabdian selesai, post-test pun dilakukan untuk mengukur sejauh mana peningkatan pengetahuan dari mitra. Hasilnya, 95\% atau 38 peserta menyatakan pengetahuan mereka mengenai diseminasi dan publikasi karya tulis meningkat. Sementara itu, sisanya karena suatu hal tidak dapat mengikuti post-test yang dilakukan. Adapun sebagai upaya untuk menjaga kesinambungan dengan mitra kegiatan meskipun kegiatan pengabdian ini telah selesai dilaksanakan, tim pengabdian tetap memberikan keleluasaan untuk para santri untuk tetap berdiskusi dan berkonsultasi terutama berkaitan dengan kepenulisan sesuai dengan fokus utama kegiatan pengabdian yang telah bersama-sama diselenggarakan. Harapan besar dari kegiatan pengabdian yang telah dilakukan adalah agar para santri yang juga merupakan remaja dapat berpartisipasi dan memberi kontribusi positif bagi proses pembangunan bangsa. Dan hal ini dimulai dari apa yang mereka dapat lakukan di mana salah satunya adalah menyebarkan gagasan, semangat dan narasi yang baik melalui dunia tulismenulis.

\section{SIMPULAN}

Pengetahuan mengenai berbagai cara dan pilihan untuk mendiseminasikan dan mempublikasikan karya tulis atau tulisan yang telah dihasilkan para santri sangat diperlukan. Hal ini tak lain dimaksudkan agar karya tulis yang mereka hasilkan dapat dibaca khalayak yang lebih luas sehingga pesan-pesan kebaikan, moral dan islami yang terkandung di dalamnya dapat menyebar luas. Para santri berharap karya tulis yang mereka hasilkan dapat menjadi sumber bacaan alternatif yang baik dan dalam derajat tertentu dapat memberikan inspirasi yang positif bagi siapapun yang membacanya.

Berbekal pengetahuan dan keterampilan yang telah mereka miliki ini mereka dapat memilih mana media yang dapat menjadi sarana terbaik untuk mempublikasikan karya tulis mereka di masa yang akan datang. Secara keseluruhan kegiatan pengabdian ini mendapatkan respons positif dari para santri. Menurut mereka kegiatan semacam ini sangat bermanfaat karena mereka dapat memperoleh pengetahuan dan keterampilan baru yang sebelumnya belum mereka miliki. Hal ini dibuktikan dari antusiasme para santri yang mengikuti kegiatan pengabdian sejak awal hinggal akhir. Mereka pun berharap agar kegiatan pengabdian berkaitan dengan dunia tulis-menulis dapat dilaksanakan kembali di pondok pesantren mereka.

\section{UCAPAN TERIMA KASIH}

Tim pengabdian kepada masyarakat menghaturkan terima kasih atas segenap dukungan yang diberikan oleh pihak mitra khususnya Bapak Muhammad Doby dan Ibu Endang Komalasari selaku pembina dan pengajar di Pondok Pesantren Rumah SETIA. Selain itu, 
apresiasi dan ucapan terima kasih juga kami sampaikan kepada seluruh santri yang telah mengikuti kegiatan pengabdian dengan penuh semangat.

\section{DAFTAR PUSTAKA}

Alkhajar, E. N. S. 2007. Hiperealitas dalam Kehidupan Nyata. Kompas, 31 Desember.

Alkhajar, E. N. S. 2009. Televisi, Hiperealitas dan Media Literacy. In E. N. S. Alkhajar et al., Anomi Media Massa (pp. 9-31). Surakarta: Pascasarjana Ilmu Komunikasi UNS.

Alkhajar, E. N. S. 2010. Sinetron dalam Balutan Industri Budaya. Pelita, 29 April.

Alkhajar, E. N. S. 2011. Televisi dan Energi Pembangun Bangsa. Komunikasi Massa, 4(1), 107-118.

Alkhajar, E. N. S. 2014. Media, Masyarakat dan Realitas Sosial. Surakarta: Sebelas Maret University Press.

Alkhajar, E. N. S., \& Luthfia, A. R. (2020). Daur Ulang Sampah Plastik Sebagai Mitigasi Perubahan Iklim. Penamas Adi Buana, 4(1), 61-64.

Chomaria, N. 2014. Cara Mencintai Anak Yatim. Solo: Aqwam.

Dasuki, M. N. 2011. 100 Pesanan Terakhir Rasulullah. Selangor: Grup BukuKarangkraf.

Luthfia, A. R., \& Alkhajar, E. N. S. 2011. Pelabuhan Terakhir. Surakarta: Bukutujju.

Luthfia, A. R., \& Alkhajar, E. N. S. 2018. Strengthening Public Awareness on Climate Change: Lesson Learned from a Youth Social Movement in Yogyakarta, Indonesia. IOP Conference Series: Earth and Environmental Science, Vol. 200, 012033. DOI :10.1088/1755-1315/200/1/012033

Luthfia, A. R., Alimin, N. N., Nugraheni, F. S. A., \& Alkhajar, E. N. S. 2019a. Penguatan Literasi Perubahan Iklim di Kalangan Remaja. Abadimas Adi Buana, 3(1), 39-42.

Luthfia, A. R., Alkhajar, E. N. S., Sudibyo, D. P., Haji, S., \& Nurharjadmo, W. (2019b). Penulisan Fiksi Sebagai Wahana Artikulasi Gagasan Generasi Muda. Bakti Cendana, 2 (2), 66-70.

Muhsin M.K. 2003. Mari Mencintai Anak Yatim. Jakarta: Gema Insani Press.

Santrock, J. W. 2010. Adolescence. New York: McGraw-Hill.

Santrock, J. W. 2013. Life-span Development. New York: McGraw-Hill.

Sarwono, S. W. 2011. Psikologi Remaja. Jakarta: PT. Raja Grafindo Persada.

Shaffer, D. R., \& Kipp, K. 2010. Development Psychology: Childhood and Adolescence (8th Ed.) Belmont, CA: Wadsworth, Cengage Learning.

Wirodono, S. 2005. Matikan TV-Mu. Yogyakarta: Resist Book. 